\title{
Cultura material en "clausura": las reliquias del Monasterio de las Descalzas Reales en los siglos XVI y XVII*
}

\author{
Material culture in "cloister": the relics of the Descalzas Reales' \\ monastery in the $16^{\text {th }}$ and $17^{\text {th }}$ centuries
}

\section{Esther Jimenez Pablo'}

\section{RESUMO}

El monasterio de las Descalzas Reales destacó por albergar a mujeres de la familia real. Fundado en 1559 por la princesa Juana, hermana de Felipe II, profesaron en dicho monasterio personalidades tan destacadas como la emperatriz María -también hermana del rey Prudente-, o la hija de la misma, sor Margarita de la Cruz. Al mismo tiempo que era un lugar visitado por numerosas reinas, princesas e infantas de la Monarquía hispana y de otros reinos. Pero también era un espacio de poder, un palacio femenino, en cuyo interior se albergaba una de las mayores colecciones de reliquias y relicarios como regalos particulares a estas mujeres reales. No había embajador, nuncio o legado que no trajera una cajita con reliquias para las ilustres monjas del monasterio. Por su importancia, su valor simbólico, y también diplomático, y por ser su cuidado una de las actividades principales de este centro religioso, las reliquias del Monasterio de las Descalzas Reales merecen ser estudiadas como objetos de culto, pero también, como regalos en el ámbito de poder.

Palavras-chave: Descalzas Reales, reliquias, relicarios, clarisas, diplomacia.

\section{ABSTRACT}

The monastery of the Descalzas Reales is known for housing women of the royal family. It was founded in 1559 by Princess Juana, sister of Philip II, and many prominent figures professed in this monastery, like the Empress Maria - also sister of the Prudent King-, or her daughter, sor Margarita de la Cruz. At the same time this place was visited by numerous queens, princesses and infants of the Hispanic Monarchy and from the other kingdoms. But it was a space of power too, a feminine palace with one of the largest collections of relics and reliquaries as private gifts to these royal women. There was no ambassador, nuncio, or legate who did not bring a box with relics for the illustrious nuns of the monastery. Due to their importance, their symbolic and diplomatic value, and because its care was one of the main activities in this religious center, 
the relics of the Monastery of the Descalzas Reales deserve to be studied as objects of worship, but also as gifts in the sphere of power.

Keyword: Descalzas Reales, relics, reliquaries, Poor Clares, diplomacy

La difusión de las reliquias sagradas en la Europa católica ha sido estudiada como una reacción de la reforma católica - postridentina- al feroz ataque luterano y calvinista que desacreditaba el valor simbólico de las reliquias, y lo empañaba de incredulidad y superstición. Cierto es que en el Concilio de Trento se reafirmó la importancia de las reliquias para el mundo católico, multiplicándose el interés por conservar estos restos de santos y mártires capaces de obrar milagros (MÂLE, 2001: 126-127). Estos vestigios de santidad eran depositados en centros religiosos como iglesias, conventos, pero también en palacios, casas nobiliarias e incluso en casas más humildes cuyos padres dejaban en herencia a sus hijos estas pequeñas piezas tan preciadas (GONZÁLEZ LOPO, 1993: 247). El caso que analizaré en las siguientes páginas es la colección de reliquias del Monasterio de las Descalzas Reales, que contaba con más de 400 reliquias, hoy muchas de ellas desaparecidas, siendo el $98 \%$ de esta colección recopilada entre los años 1570 y 1700. La mayoría de las reliquias llegaron cuando residían en el monasterio la emperatriz María (1528-1603), esposa del emperador Maximiliano II y hermana del monarca Felipe II (1527-1598), quien enviudó y regresó a Madrid en 1581 (GALENDE, SALAMANCA, 2004), prefiriendo vivir en clausura con su hija Margarita (15671633), otra gran devota de las reliquias (SANZ DE BREMOND, VILACOBA, 2006: 787-804, SICARD, 2011: 631-646). Se trata, por tanto, de una colección privada de reliquias, regalos particulares a estas mujeres de la familia real, que tenían una doble función; por un lado, eran obsequios de otras cortes europeas que, a través de estas mujeres, servían para afianzar las relaciones entre miembros de las distintas monarquías católicas y, por el otro, reforzaban la devoción y la piedad de las monjas clarisas descalzas que profesaban en el monasterio, siendo el cuidado de las reliquias una de las labores principales del quehacer doméstico de las monjas de la familia real.

\section{Monjas de la realeza y nobleza en el Monasterio}

Desde que la princesa Juana de Austria (1535-1573), hermana de Felipe II, por influjo de su confesor Francisco de Borja (1510-1572) (DALMASES, 1983, GARCÍA HERNÁN, 1999; SEBASTIÁN, 2010: 67-90), fundara el monasterio de las Descalzas Reales en 1559, sirvió como lugar de recogimiento para las mujeres de la familia real y de la alta nobleza (VILACOBA, MUÑOZ SERRULLA, 2010: 115-156), donde practicar una observancia y espiritualidad radical. Antiguo palacio del tesorero del emperador Carlos V, don Alonso Gutiérrez, quien puso a disposición de la emperatriz Isabel de Portugal su casa para que diera a luz a la princesa Juana en 1535 (PORTÚS PÉREZ, 1998: 2-12, RODRÍGUEZ, 1998: 13-24, SÁNCHEZ, 2015: 53-82). Había sido, por tanto, un antiguo palacio reconvertido en monasterio, y en este sentido, la princesa 
Juana lo remodeló para hacer las estancias más adaptadas a la vida monacal. Por fuera el monasterio presenta un aspecto sobrio, con muros de ladrillo y mampostería, por dentro, la decoración es la de un palacio real con la impresionante pintura mural de la escalinata principal y sus numerosos retratos reales, tapices, belenes y retablos, que todavía hoy deslumbran a los visitantes (TORMO Y MONZÓ, 1944, JUNQUERA, JUNQUERA, 1969: 18-31).

En él, además de haber residido la princesa Juana, vivió permanentemente la emperatriz María de Austria (viuda del emperador Maximiliano II) desde el 25 de enero de 1584, y su hija la infanta Margarita, quien profesó la regla de Santa Clara (en su versión descalza) con el nombre de sor Margarita de la Cruz (SÁNCHEZ, 1998: 777-794). Asimismo, visitaban asiduamente las Descalzas Reales, las hijas de Felipe II, es decir, las infantas Isabel Clara Eugenia (1566-1633) y Catalina Micaela (1567-1597), antes de que las jóvenes contrajeran sus respectivos matrimonios y se marcharan. Más tarde, la propia Isabel Clara Eugenia favoreció en Flandes la expansión del movimiento descalzo, fundando conventos de carmelitas descalzas, y cuando enviudó y quedó como gobernadora, decidió tomar el hábito de franciscana terciaria en el convento de Bruselas (VAN WYHE, 2004: 416). Por su parte, a partir de 1628, profesó en las Descalzas Reales Ana Dorotea de Austria (1612-1694), hija del emperador Rodolfo II (VILACOBA, 2005: 643-661. A la muerte de su padre y de su tío el emperador Matías, la joven fue llamada por su tía sor Margarita de la Cruz para que residiera con ella en las Descalzas Reales (VILACOBA, MUÑOZ SERRULLA, 2010:128). A estas mujeres de la realeza que vivían en clausura, habría que añadir el elevado número de damas e hijas de la nobleza que profesaron en este monasterio de patronato real durante los siglos XVI y XVII(AMORÓS, 1960: $479)^{2}$, tal y como se muestra en el siguiente listado en el que se recogen las monjas que profesaron entre los años 1554 y 1665 (ÁLVAREZ SOLAR-QUINTES, 1962: 50-55, GIL RUIZ, 2000: 31-56):

Quadro 1 - Nombre mujeres y familiares

\begin{tabular}{|c|c|}
\hline Margarita de Austria & Hija de la emperatriz María de Austria \\
\hline Catalina María de Este y Saboya & $\begin{array}{l}\text { Hija de los príncipes de Módena, nieta de la infanta } \\
\text { Catalina y del duque de Saboya }\end{array}$ \\
\hline Ana Dorotea de Austria & Hija de Rodolfo II de Alemania \\
\hline Mariana de Austria & $\begin{array}{l}\text { Hija del infante don Fernando, gobernador de los Países } \\
\text { Bajos }\end{array}$ \\
\hline Margarita de Austria & Hija de don Juan José de Austria \\
\hline Buenaventura Tebes y de Brito & Hija de un caballerizo mayor de doña Juana de Portugal \\
\hline Ana Molar y Casellance & $\begin{array}{l}\text { Hija de un caballerizo mayor de la Emperatriz María, y } \\
\text { de la aya de la infanta Margarita y de la infanta Leonor }\end{array}$ \\
\hline Agustina de Zárate & Camarera de la reina Ana de Austria \\
\hline
\end{tabular}

${ }^{2}$ P. Fray Juan Carrillo, Relación Histórica de la real fundación del Monasterio de las Descalças de S. Clara de la villa de Madrid, Madrid, 1616, fol. 20v (Biblioteca Nacional de España, 2/64187). 


\begin{tabular}{|c|c|}
\hline Cecilia de la Cruz & Dama de Juana de Portugal y de la reina Ana de Austria \\
\hline Luisa de Pernestan y Manrique & $\begin{array}{l}\text { Hija del gran canciller de Bohemia y de una dama de la } \\
\text { Emperatriz María }\end{array}$ \\
\hline Rafaela Madrigal y Cardona & Condes de Villasolís, dama de la Emperatriz María \\
\hline Ana Moscoso y Rojas Sandoval & $\begin{array}{l}\text { Hija de mayordomo de la reina Margarita de Austria, } \\
\text { Condes de Altamira }\end{array}$ \\
\hline Ana de Benavides y de la Cerda & Hija de un Consejero Real de Indias \\
\hline María de Benavides y de la Cerda & Hija de un Consejero Real de Indias \\
\hline Felipa de Tovar & Hija de un Consejero del Rey y secretario de Cámara \\
\hline Francisca de Borja & Duques de Gandía \\
\hline Juana de Borja y Aragón & Duques de Gandía \\
\hline Juana de Borja y Aragón & Duques de Gandía \\
\hline María de Borja y Aragón & Duques de Gandía \\
\hline Ana María Juana Borja y de Castro & Duques de Gandía \\
\hline Isabel Borja y Enríquez & Duques de Gandía \\
\hline Magdalena de Borja & Duques de Gandía \\
\hline Juana de Borja y de Luna & Duques de Gandía \\
\hline Pía María de Borja y de Córdoba & Duques de Gandía \\
\hline María Rojas Sandoval y Enríquez & Marqueses de Denia y condes de Lerma \\
\hline Francisca Rojas y Sandoval & Marqueses de Denia y condes de Lerma \\
\hline María Prógita y de Borja & Condes de Almenara \\
\hline $\begin{array}{l}\text { Leonor Rojas Moscoso y Mendoza } \\
\text { Sandoval }\end{array}$ & Condes de Altamira y marqueses de Almazán \\
\hline $\begin{array}{l}\text { Margarita Rojas Moscoso y Mendoza } \\
\text { Sandoval }\end{array}$ & Condes de Altamira y marqueses de Almazán \\
\hline Gesualda Rojas y Fernández de Córdoba & Duques de Gandía \\
\hline Francisca de Trejo y Jaúregui & Marqueses de la Rosa \\
\hline Jerónima de Trejo y Jaúregui & Marqueses de la Rosa \\
\hline Ana de Almeida & Marqueses de Aguilafuente \\
\hline Ana de Zúñiga y Cabrera & Marqueses de Aguilafuente \\
\hline Luisa Zúñiga y Cabrera & Marqueses de Aguilafuente \\
\hline Juliana Fernández Manrique y Velasco & Condes de Osorno \\
\hline Angela Fernández Manrique y Velasco & Condes de Osorno \\
\hline Leonor Pacheco y de Toledo & Marqueses de Cerralbo y Condes de Alba de Liste \\
\hline Francisca Pacheco y de Toledo & Marqueses de Cerralbo y Condes de Alba de Liste \\
\hline María Pacheco y Mendoza & Señores de Minaya y Valdemara. \\
\hline Ana María Pacheco y Mendoza & Señores de Minaya y Valdemara \\
\hline Ana Pacheco y Mendoza & Señores de Minaya y Valdemara \\
\hline Leonor de Toledo & Casa de Alba y condes de Alba de Liste \\
\hline Francisca Cobos de Mendoza y Guzmán & Marqueses de Camarasa \\
\hline
\end{tabular}




\begin{tabular}{|c|c|}
\hline María de Aragón y Gurrea & Duques de Villahermosa \\
\hline Juana de Aragón y Gurrea & Marqueses de Villahermosa \\
\hline Juana de Gurrea y Villalpando & $\begin{array}{l}\text { Marqueses de Navarres y señores de la Baronía de } \\
\text { Gurrea }\end{array}$ \\
\hline María de Castro y Gatinara & Condes de Lemos \\
\hline María Bazán y Manuel & Marqueses de Santa Cruz \\
\hline Cándida Bazán y Manuel & Marqueses de Santa Cruz \\
\hline Felice de Velasco & Condes de Fuensalida \\
\hline Isabel Benavente y Neli de Rivadeneira & Condes de Fontanar \\
\hline $\begin{array}{l}\text { Violante Benavente y Neli de } \\
\text { Rivadeneira }\end{array}$ & Condes de Fontanar \\
\hline $\begin{array}{l}\text { Catalina Fernández Pacheco y de } \\
\text { Portugal }\end{array}$ & $\begin{array}{l}\text { Duques de Escalona, marqueses de Villena, condes de } \\
\text { Santisteban y Xiquena }\end{array}$ \\
\hline Juana Fernández Pacheco y de Portugal & $\begin{array}{l}\text { Duque de Escalona, marqueses de Villena, condes de } \\
\text { Santisteban y Xiquena }\end{array}$ \\
\hline Juana María de Mendoza y Portocarrero & Marqueses de Almazán y condes de Monteagudo \\
\hline Juana Portocarreor y de Luna & Condes de Montijo y Condes de Fontidueña \\
\hline $\begin{array}{l}\text { Margarita Fernández de Córdoba y } \\
\text { Portocarrero }\end{array}$ & Condes de Teba y marqueses de Ardales \\
\hline Juana María de Guzmán y Portocarrero & Marqueses de La Algaba \\
\hline Ana María Josefa de Chaves y Lugo & Marqueses de Cardeñosa \\
\hline Isabel María Chacón y Ayala & Señores de Casarrubios del Monte \\
\hline Ana Antonio Aranda y Almaguer & Marqueses de Maenza \\
\hline María Ávila Enríquez & Marqueses de las Navas \\
\hline Mercedes González Torres y Navas & Marqueses de Campoverde \\
\hline Antonio Gonzáles Torres y Navas & Marqueses de Campoverde \\
\hline Joaquina María Cemecio y Guzmán & Condes de Parcent \\
\hline Ana María Cemecio y Guzmán & Condes de Parcent \\
\hline Serafina Pardela y Pacheco & Príncipes de Pacheco y marqueses de San Lorenzo \\
\hline María Encarnación Muro y Salazar & Marqueses de Someruelo \\
\hline Teresa María Pérez y Arellano & Marqueses de Someruelo \\
\hline Leandra María Besante y Mesía & Condes de Molina \\
\hline Francisca Javiera Besante y Mesía & Condes de Molina \\
\hline Antonia María Porcel y Cañaveral & Marqueses de Villa Alegre \\
\hline María Dolores Porcel y Cañaveral & Marqueses de Villa Alegre \\
\hline $\begin{array}{l}\text { María Mariana Lasso de la Vega y } \\
\text { Dávila }\end{array}$ & Condes de Arcos \\
\hline Faustina Castellón y de Híjar & Marqueses de Cea \\
\hline Tomasa Somara y Onís & Marqueses de Castel de los Ríos \\
\hline María Teresa Cebrián Aragón Pimentel & Condes de Fuenclara \\
\hline $\begin{array}{l}\text { Manuela Antonio Barradas } \\
\text { Portocarrero y Bazán }\end{array}$ & Marqueses de Corte y Baena \\
\hline
\end{tabular}




\begin{tabular}{|c|c|}
\hline María Josefa Barradas y Bazán & Marqueses de Cortes y Baena \\
\hline $\begin{array}{l}\text { Angela María Barradas Portocarrero y } \\
\text { Fernández de Henestrosa }\end{array}$ & Marqueses de Cortes \\
\hline $\begin{array}{l}\text { María de Pópulo Arrese Bernuy y } \\
\text { Quesada de Toledo }\end{array}$ & Marqueses de Villanueva del Castillo \\
\hline $\begin{array}{l}\text { Rosalía María Rita Arrese Bernuy y } \\
\text { Quesada de Toledo }\end{array}$ & Marqueses de Villanueva del Castillo \\
\hline María Portocarrero y de la Cerda & Condes de Montijo \\
\hline Catalina de Vargas y Pacheco & Condes de Puerto \\
\hline Isabel Valladares y Oferes Silva & Condes de Tepinares \\
\hline Jacinta Valladares y Oferes Silva & Condes de Tepinares \\
\hline Luisa de Velasco y de la Cueva & Condes de Siruela \\
\hline Teresa Bolea y Almadén & Marqueses de Torres \\
\hline María Villanueva y Barradas & Condes de Alba Real \\
\hline María Teresa Villanueva y Barradas & Condes de Alba Real \\
\hline Mariana Zapata y Silva & Condes de Barajas \\
\hline María Clara de Alarcón y Andrade & Marqueses de Palacios y Señores de Buenache \\
\hline María Magdalena Ramírez y Córdoba & Marqueses de La Algaba \\
\hline Ana María del Yermo y Avila & Marqueses de Lorenzana \\
\hline $\begin{array}{l}\text { Margarita Fernández de Córdoba y } \\
\text { Portocarrero }\end{array}$ & Marqueses de Lorenzana \\
\hline María Manrique y Porsida & Marqueses de Cañete \\
\hline
\end{tabular}

A pesar del alto rango de todas estas monjas, es probable que la clausura de estas mujeres lleve a pensar que no participaban en las cuestiones políticas de su momento, no obstante, las continuas visitas de ministros, nuncios, embajadores, y de familiares de la casa real, confirman la fuerte conexión que existía entre las Descalzas Reales y el antiguo Alcázar de Madrid, a la vez que el monasterio era un lugar lo suficientemente apartado del palacio como para tratar con mayor tranquilidad negocios relacionados con el gobierno de la Monarquía. ${ }^{3}$ En particular, las monjas que pertenecían a la familia real gozaban de un privilegio papal para poder recibir visitas externas. Sabemos que numerosos embajadores y nuncios papales, a su llegada a Madrid, pasaban por las Descalzas Reales para visitar a estas ilustres monjas, trayendo consigo una cajita de reliquias en nombre de los dignatarios a los que representaban, como obsequio por ser el regalo más preciado para estas mujeres. De forma que numerosos monarcas europeos, pontífices romanos e importantes nobles, supieron valorar el papel espiritual del convento de las Descalzas Reales, al mismo tiempo que fueron conscientes del espacio de influencia en el que, siempre de manera indirecta, se había convertido este monasterio con respecto al cercano Alcázar Real (MARTÍNEZ MILLÁN, 1999:143-162). Y es en este contexto cómo, en forma de regalos, llegaban reliquias de toda

\footnotetext{
${ }^{3}$ En numerosas cartas se constatan las continuas visitas a estas mujeres de ministros tan destacados como don Juan de Zúñiga, conde de Miranda, presidente del Consejo de Castilla. British Library, Add. Mss. 28,422, f. 354r. Madrid, 9 de marzo de 1600 .
} 
Europa a este convento, para las mujeres de la realeza que en un momento dado podía influir en las decisiones del monarca hispano.

El análisis de las visitas de ministros y familiares reales que recibían la emperatriz María y su hija en el convento, revela la fuerte dependencia que existía entre el monasterio y la corte madrileña. A menudo, el monarca Felipe III (1578-1621) y su esposa Margarita de Austria (15841611), acompañados de los infantes, acudían al monasterio que distaba del antiguo Alcázar en unos 700 metros, para visitar a la emperatriz y la infanta. En otros estudios de las Descalzas Reales he analizado cómo este monasterio no sólo era una órbita de poder de la corte hispana, sino que también se convirtió en un lugar de oposición al gobierno del valido de Felipe III, don Francisco de Sandoval (1553-1625), I duque de Lerma (JIMÉNEZ PABLO, 2012: 125-136). Éste siempre se quejó de las continuas visitas de los reyes a las monjas y cómo la emperatriz y su hija no eran una buena influencia para los reyes. ${ }^{4}$

\section{Las reliquias sagradas de las Descalzas Reales}

El monasterio de las Descalzas Reales ocupaba toda una manzana que incluía la Iglesia y los distintos espacios de autoabastecimiento de las monjas como las huertas, las vaquerías o la tahona. Así mismo, desempeñaba una labor social importante pues era un gran centro benéfico de la villa de Madrid: hospital de misericordia y colegio de niñas huérfanas.

Si observamos la actual planta del monasterio de las Descalzas Reales, podemos distinguir las distintas estancias y la amplitud de un palacio (OLIVERAS, 1970: 73-76, ANDRADA, 1969: 65-67). La princesa Juana buscó un edificio que no se limitara únicamente a la creación de un lugar religioso ocupado por una comunidad de clarisas, sino que su proyecto iba más lejos, contemplaba la remodelación de espacios con una función religiosa mezclada con el carácter cortesano, entre los que se encontraban su propio aposento y un panteón dentro del monasterio (GARCÍA SANZ, 2010: pp. 9-32). Paralelamente, su hermano Felipe II se estaba construyendo el Monasterio del Escorial, residencia, panteón, y casa de una comunidad religiosa. Proyectos paralelos en los que las reliquias y su culto iban a ser los objetos fundamentales que determinaban los espacios (fig. 1).

\footnotetext{
${ }^{4}$ Sobre los celos del valido de Felipe III se señala que: Bueltos a Madrid de sus bodas el rey y la reyna fueron luego a visitar a la Emperatriz con que se resucitaron de nuevo los zelos el duque, temiendo que las lecciones que la nueva reyna oyría de la Emperatriz y de su hija la infanta doña Margarita podrían ser en perjuicio de su privança. En particular tomó muy mal que las dos primas se hablassen en alemán, y no pudiéndolo estorvar procuró que por lo menos se viesen las menos vezes que fuesse possible, lo qualdio no poco cuidado a la Emperatriz, entendiendo que no avía de parar en bien de su nieto. Valladolid, 1 de enero de 1606. Cita de LABRADOR, 2001: 618-619.
} 


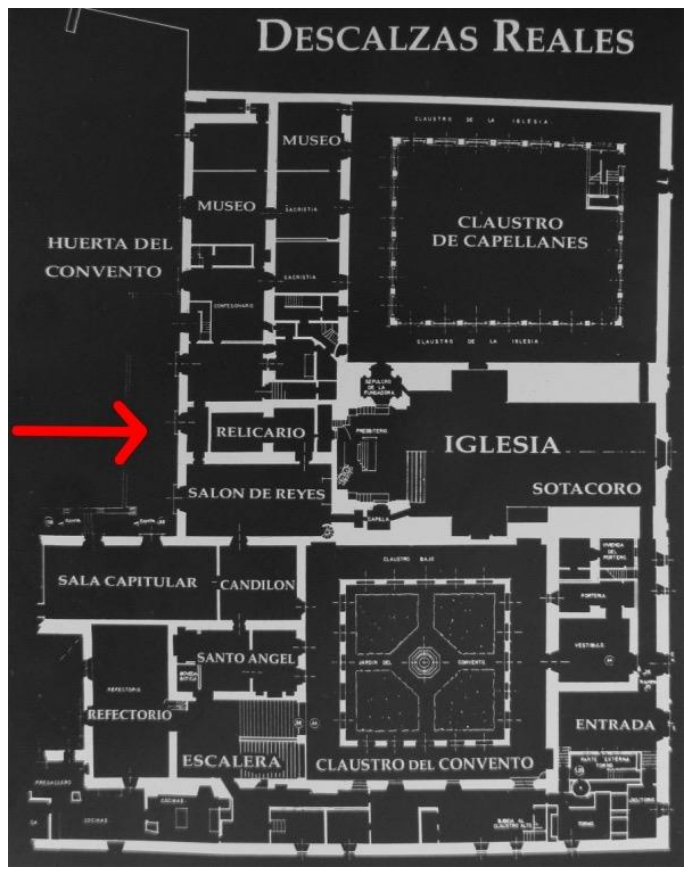

Fig. 1. Planta de las Descalzas Reales. Imagen extraída de la obra de GUERRA DE LA VEGA, 1996: 79.

En la planta de las Descalzas Reales podemos observar que el Relicario es una pequeña habitación en el corazón del monasterio. De manera que es un lugar importante, probablemente la estancia más preciada para las monjas. Se sitúa justo detrás del altar mayor de la Iglesia de las Descalzas (GARCÍA SANZ, 2014: 1). Pero además de la sala relicario, un total de 25 capillas guardan importantes reliquias que forman la colección de más de 400 reliquias. No son las 7.422 reliquias que Felipe II recopiló en El Escorial pero es una muestra de la importancia de este convento en para la sacralidad de la Monarquía. ${ }^{5}$

En cuanto al estudio de las reliquias sagradas que se guardaban en las Descalzas Reales es preciso tener en cuenta que hoy ha desaparecido buena parte de la colección a causa del incendio que sufrió en 1862. A lo que habría que sumar la devastadora acción de la guerra civil española (1936-1939) que provocó el derrumbe de una parte del monasterio -hoy ya rehabilitado- afectando, entre muchos otros objetos de valor espiritual y artístico, a la mayoría de los relicarios (RUIZ ALCÓN, 1975: 34-36). De manera que para poder reconstruir el conjunto de reliquias que existieron en las Descalzas Reales durante los siglos XVI y XVII, es preciso consultar las "auténticas" de las reliquias (González Lopo, 1993: 248). Se trataba de documentos que acreditaban la autenticidad de la reliquia a la que acompañaban, garantizando su validez, dándole el valor sagrado para ser adorada por los fieles. Las auténticas eran firmadas y aprobadas por un cargo elevado de la Iglesia Católica, bien un

${ }^{5}$ Felipe II confiaba en el valor sanador de las reliquias que coleccionó. En su lecho de muerte pidió que le acercaran distintas reliquias para ayudarle a bien morir. Las reliquias que se custodian en El Escorial son en su mayoría de santos hispanos. En SOLER VILLALOBOS, 2011: 82. 
cardenal, un arzobispo, un obispo, etc. Este procedimiento por el que toda reliquia apta para su culto debía llevar su certificado de autenticidad se impuso durante el Concilio de Trento, en un intento por poner obstáculos a la difusión de reliquias fraudulentas. No obstante, esto no impidió el tráfico de reliquias que se generó en toda Europa durante los siglos XVI y XVII, al no cuestionarse en muchos casos ni el origen ni la autenticidad de las reliquias que se guardaban en los centros religiosos. A pesar de que hay que tener en cuenta todas estas valoraciones a la hora de analizar las reliquias, la mayoría de las que se custodian en las Descalzas Reales, por la importancia del lugar y el rango de quienes enviaban las reliquias y de las mujeres que profesaba en el monasterio, llevaban consigo la auténtica, y es precisamente esta certificación la que nos permite conocer el tipo y la procedencia de las reliquias de las Descalzas Reales en época barroca ${ }^{6}$.

\section{El tipo de reliquias: santos y mártires de la Iglesia primitiva}

El 90 \% de las reliquias son restos óseos de santos y mártires de la Iglesia primitiva, como san Ambrosio, san Simón, santa Constancia, san Adrián, santa Cristina, santa Dorotea, santa Úrsula, y de mujeres mártires que permanecieron vírgenes. Cabe señalar que la mayoría de las reliquias de estos mártires eran mujeres, reflejo de la devoción de las monjas del monasterio por el modelo de mujer fuerte que daba su vida por la fe como era el caso de santa Úrsula, con sus compañeras, las once mil vírgenes, de las que existen diversos restos en la colección ${ }^{7}$.

Otro grupo importante de reliquias, aunque escaso en su número, se aproximan en total a unas veinte reliquias, fueron las de personajes coetáneos a la emperatriz María y su hija sor Margarita de la Cruz, como por ejemplo religiosos beatificados o canonizados durante el siglo XVII como Teresa de Jesús, Ignacio de Loyola, Felipe Neri, Francisco de Borja, etc. En este caso no se trataba de restos humanos, sino que eran fragmentos del atuendo que llevaban, como podían ser pañuelos, capas, retal del hábito, sotana, porque a menudo estos santos coetáneos conservaban sus "cuerpos incorruptos", preservados ante la acción del tiempo, y guardados como auténticas joyas en las principales catedrales o iglesias barrocas. Concretamente, era muy preciada la gota de sangre de la célebre santa carmelita Teresa de Jesús ${ }^{8}$, también una manga del jubón de la misma Santa ${ }^{9}$, o la sangre del arzobispo de Milan San Carlos Borromeo, al que habían conocido la emperatriz y su hija, a su paso por Milán ${ }^{10}$, cuando viajaban de Viena

\footnotetext{
${ }^{6}$ Se han consultado: Archivo General de Palacio (AGP), PC, Reales Descalzas, cajas 79, 84, 85, 86, y Cajones 2/1, 2/2, 4/2, 4/3, $4 / 5,5 / 1,5 / 2,5 / 3,6 / 1,6 / 3,6 / 4,7 / 2,7 / 4,7 / 6,8 / 1,8 / 4,8 / 7,9 / 3,9 / 4,9 / 5,9 / 6$.

${ }^{7}$ Sobre la mujer y el martirio en el cristianismo desde el revisionismo feminista en ZURIAGA SENENT, 2012: 157-177; PEDREGAL, 2000: 277-294; BASTIDA, 2000: 191-207.

${ }^{8}$ AGP, PC, Reales Descalzas, caja 86, exp. 60.

${ }^{9}$ Ibidem, cajón $2 / 1$.

${ }^{10}$ De camino a Madrid, en Lodi, realizó la comitiva una parada para que la emperatriz María se reuniese con el cardenal Carlos Borromeo, con el que ella y la infanta Margarita mantuvieron una estrecha relación epistolar hasta la muerte del cardenal en 1584. Durante esos días en Lodi, las crónicas detallan cómo estas dos mujeres trataron con el cardenal
} 
a Madrid ${ }^{11}$. La sangre de Santa Teresa venía acompañada de su auténtica que además de certificar su veracidad, explicaba la esencia de esta reliquia cuya sangre se había impregnado en el jubón de Teresa de Jesús y parecía que la mancha estaba siempre húmeda cambiando constantemente de forma. Esta gota de Santa Teresa era utilizada en periodos de grave enfermedad de alguna de las monjas del convento, colocándolo en el lugar exacto del dolor, que ejercería una supuesta acción curativa.

Había dos reliquias que por su importancia y valor eran veneradas con gran devoción en el Monasterio. Por un lado el Lignum Crucis, del que sabemos que cuando la princesa Juana o después la emperatriz María padecían fiebres tercianas, pedían a las monjas que sumergieran el Lignum Crucis en agua, porque confiaban que bebiendo dicha agua, donde había sido bañado el fragmento de la cruz de Cristo, serviría para curar la enfermedad inmediatamente. Las crónicas cuentan cómo al sumergir este pedacito de la madera, el agua se teñía de sangre al contacto con la reliquia. En una de las hagiografías del jesuita san Francisco de Borja, confesor de la princesa Juana, se narraba el aprecio de esta mujer por la reliquia:

Dijo un día la Princesa a Francisco, que tenía un grande pedazo de Lignum Crucis, cuyo color era algo más claro, que aquel milagroso; y que por esso dudaba, si fuesse verdadera astilla del Arbol que redimió al Mundo: que la grande fee, e igual experiencia, que tenía en la luz de Francisco de Borja, la dejarían totalmente asegurada, si él dijese su dictamen en esta materia: Tomó el Lignum Crucis en la mano el Santo Borja, haciendo una breve pausa en la vista, y dentro del alma, para recoger allá luz misteriosa; y luego con grande asseveracion dijo: Bien puede estar segura V.A. que este es legitimo fragmento de aquel Arbol de la Vida, que bañó en su sangre el Autor de ella; y partiéndole con reverencia animosa, empezó a correr sangre gota a gota, hasta teñir todo el papel, sobre que le dividia, estando presente, y llena de admiración la Princesa, y algunas criadas suyas, que ilustraron aquella Descalcez gloriosa. (CIEN-FUEGOS, 1754: 287).

Además del Lignum Crucis, la otra reliquia preciada por las monjas era la del Santo Pesebre, una paja del pesebre del niño Jesús, regalo de Bruselas de la infanta Isabel Clara

Borromeo la idea que tenía la joven Margarita de profesar como monja, y la respuesta del cardenal animando a la joven a que continuase con su idea de ser religiosa. En TORMO Y MONZÓ, 1917: 173-175.

${ }^{11}$ AGP, PC, Reales Descalzas, caja 86, exp. 27. 
Eugenia. Que se depositó guardada en una caja de oro y plata, en una pequeña capilla del ángulo noroeste del claustro.

\section{Los Relicarios: regalos de valor para las monjas}

En el caso de las Descalzas Reales, tan importante era la reliquia como el relicario o arqueta que la contenía, que era en realidad lo que más se veía. Estos lujosos objetos servían para proteger a la reliquia, evitando que ésta fuera tocada o se degradara por el contacto con los agentes externos medioambientales o antrópicos. Asimismo, tenían otra función muy clara: permitir el traslado del preciado resto humano al altar mayor o la veneración de la reliquia en procesiones ante la multitud de devotos.

La mayoría de los relicarios del monasterio habían sido regalados a las monjas. En ocasiones eran objetos reutilizados, es decir, en su origen habían sido joyeros, escritorios de viaje $o$ arcas y arquetas de traslado, elaborados con una fina orfebrería ornamentada con relieves y pequeñas figuras, que se habían reconvertido en los contenedores de estos valiosos restos (RUIZ ALCÓN, 1975: 28-36). Los escritorios, al contar con múltiples compartimentos, eran ideales para guardar diversas reliquias, mientras que las arquetas doradas y plateadas conservaban las reliquias más apreciadas. En la colección de relicarios de las Descalzas se cuenta con piezas exóticas de los siglos XVI-XVII procedentes del comercio con Asia y los virreinatos americanos. No resulta extraño que objetos de Japón tan demandados por las élites hispanas como cajas o joyeros decorados con laca namban los encontremos con una función religiosa en las colecciones de relicarios del monasterio de las Descalzas y el de la Encarnación. No hay que olvidar que la mayoría de las monjas de estos conventos de patronato real eran hijas de nobles, y por lo tanto, algunos de sus objetos de uso civil pasaron a ser relicarios (GARCÍA SANZ, SÁNCHEZ HERNÁNDEZ, 2014: 46).

De los relicarios más importantes de las Descalzas Reales es preciso destacar la arquetarelicario de san Víctor. Fue traída desde Praga por Ana de Austria en 1570, cuando llegó para convertirse en la cuarta esposa de Felipe II, junto con el resto de su dote que contemplaba una riquísima colección de relicarios. ${ }^{12}$ Como ocurrió con otras reinas, doña Ana, desde el momento que llegó a Madrid, frecuentó el monasterio de las Descalzas Reales, al que donó importantes obras de arte. Concretamente, el arca con la reliquia de san Víctor fue un regalo de Ana a su tía doña Juana, fundadora del monasterio (NIETO GALLO, 1939-1940: 177-196). De esta manera, la reliquia de san Víctor ingresó en el convento tras una solemne procesión a la que asistieron el cardenal Espinosa y los serenísimos príncipes Rodolfo y sus tres hermanos,

\footnotetext{
${ }^{12}$ Se indica que: Traxo (doña Ana) a su tía la Serenissima princesa para su monasterio, el cuerpo del glorioso mártir San Víctor, alférez de la sacra Legión de los Tébeos. Hízose solemnissima processión. Llevavan el arca donde venían las sagradas reliquias los serenissimos Príncipes Rodolfo y sus tres hermanos Archiduques Ernesto, Alberto y Venceslao (...). Venía en una arca muy rica de plata sobre terciopelo carmesí con clavazón dorada. Después de algunos días, le trasladaron a otra más rica y preciosa arca de plata dorada y esmaltada, con maravillosa obra y artificio, la qual dio la misma Reyna doña Ana a su tía la Princessa para este efecto. Cita BOUZA, 2008: 59.
} 
los archiduques Ernesto, Alberto y Wenceslao. El padre Carrillo, confesor del convento y autor de la Relación histórica de la Real Fundación del monasterio de las Descalzas, afirma en su crónica que la reina Ana sentía una gran admiración y devoción por este santo (PÉREZ DE TUDELA, 2012). En un primer momento esta reliquia se guardó en una simple arca de plata y después se trasladó a la gran arca, obra del platero Wenzel Jamnitzer de Nüremberg, quien diseñó una arqueta nupcial enriquecida de plata, oro y esmalte para el matrimonio de doña Ana. La decoración de la misma hace alusión a las virtudes del matrimonio y a la fecundidad, representando a pequeñas figuras de mujeres y niños.

Completan la colección un gran número de bustos-relicarios, los más antiguos de finales del siglo XVI, y las pequeñas imágenes que acompañan a las reliquias y que representan a los mártires cuya reliquia se coloca en una hornacina (GARCÍA SANZ, SÁNCHEZ HERNÁNDEZ, 2014: 47)

\section{La vía diplomática de las reliquias sagradas}

El análisis de las auténticas de las reliquias de 1570 a 1700 nos permite conocer la procedencia de estos restos sagrados y el interés de mantener un contacto con las monjas de las Descalzas Reales. En un sentido diplomático, es preciso advertir, que a la cajita de reliquias traída por el embajador o el nuncio le acompañaba siempre una carta en la que a veces, además de agasajar a las monjas reales y contarles detalles del culto a la reliquia regalada, se les pedía que favoreciesen algún asunto terrenal. El pontífice Clemente VIII (1592-1605), por ejemplo, a finales del siglo XVI, enviaba una caja de reliquias acompañada de una carta en la que pedía a la emperatriz María y a su hija sor Margarita que persuadiesen a Felipe II para que luchase más eficazmente en unión con la rama austriaca del Imperio para combatir la amenaza turca ${ }^{13}$. Y por supuesto, cada nuevo nuncio que llegaba a Madrid, llevaba consigo reliquias de parte del Pontífice, con una carta en la que se pedía a sor Margarita de la Cruz que diera su protección en la villa y corte madrileña al legado papal recién llegado. Este fue el caso del Papa Paulo V (1605-1621) cuando recomendaba al nuncio Francesco Cennini a la Infanta monja por carta fechada el 3 de agosto de $1618^{14}$. O cuando Gregorio XV (1621-1623) escribía a Sor Margarita el 23 de junio de 1622, para avisarle de que iba el nuncio Inocenzo Massimi a la corte madrileña, al mismo tiempo que le rogaba a la monja que protegiese al nuevo nuncio y le atendiese como si fuera el propio pontífice ${ }^{15}$.

En cuanto al lugar de origen de las reliquias de las Descalzas Reales, las auténticas revelan los siguientes datos:

\footnotetext{
${ }^{13}$ AGP, PC, Reales Descalzas, caja 84, exp. 14.

${ }^{14}$ Ibidem, exp. 15

${ }^{15}$ Ibidem, exp. 21.
} 
- El 47\% de las mismas fueron regalos enviados desde el Sacro Imperio (Alemania), es decir, que eran obsequios de familiares de estas mujeres imperiales, que mantenían contacto y se vinculaban a ellas a través de la devoción a las reliquias, que en la mayoría de las ocasiones, fueron traídas por los embajadores imperiales (VERONELLI, 1998: 517-537).

- Un $31 \%$ de las mismas procedían de Roma. En este caso se trataba de regalos enviados por el Papado a través de los nuncios. Obviamente las reliquias llegadas de Roma pertenecían todas ellas a mártires cristianos de las catacumbas romanas. A partir del año 1623 se extrajeron los restos de mártires de las catacumbas romanas de San Loreto y San Pablo. Un año más tarde, el 11 de mayo de 1624, el papa Urbano VIII (1623-1644), emitía un breve que permitía al nuncio Inocencio de Massimi extraer de Roma todas aquellas reliquias que quisiera llevar a Madrid como regalos a las monjas de las Descalzas Reales. ${ }^{16}$ De esta forma, el nuncio Inocencio de Massimi, el 25 de mayo de 1624, llevaba como obsequio a las Descalzas un conjunto de reliquias de los cuerpos de mártires como san Timoteo, san Paulino, san Anastasio, santa Rústica, san Gabino, san Felipe y san Cayo ${ }^{17}$.

- En cuanto al $22 \%$ restante, eran reliquias que provenían sobre todo de Bruselas, regalos de la infanta Isabel Clara Eugenia a su tía y a su prima en Madrid. Así como algunos restos sagrados que habían sido enviados a las monjas por parte de los virreyes americanos, pero también de los italianos (Nápoles y Sicilia), y de los gobernadores españoles de Milán.

Por lo tanto, el $78 \%$ de las reliquias formarían parte del triángulo de relaciones entre Madrid-Viena-Roma. Lo que lleva a valorar estos restos preciados como medios a través de los cuales se afianzaban las relaciones entre las distintas cortes católicas. Y, desde luego, se debe estudiar el monasterio como uno de los centros religiosos más importantes -sino el que másque orbitaba alrededor del Alcázar de Madrid y su poder político.

\section{Una actividad en manos de la realeza: el cuidado de las reliquias}

Sabemos que el cuidado de las reliquias de este monasterio estaba en manos de distintas monjas, es decir, cada monja tenía asignada una capilla con sus reliquias (ALMUDENA

\footnotetext{
${ }^{16}$ Ibidem, caja 86, exp. 30
}

${ }^{17}$ Ibidem. 
PINTOS, 2010: 79), que debían adornar con flores en época de procesiones o fiestas de santos. La actividad en las capillas se basaba principalmente en la limpieza y barrido de las mismas, incluidos los relicarios, los sábados de cada semana. Ahora bien, las reliquias de la sala relicario de las Descalzas Reales, en el corazón del monasterio, donde se guardaban la mayoría de las reliquias, y desde luego las más importantes, fueron cuidadas primero por la infanta sor Margarita de la Cruz y después por sor Ana Dorotea, es decir, que era un honor y era una de las tareas más importantes del propio cenobio, dado que estaba en manos de la monjas de mayor estatus social. El oficio se denominaba "relicarieras" (ALMUDENA PINTOS, 2010: 81). Resulta lógico que fueran ellas las encargadas, pues la mayoría de las reliquias eran regalos a estas mujeres de la familia de los Austrias, de modo que preservaban su propio patrimonio y mantenían vivos los cultos de la dinastía.

La sala relicario era igualmente limpiada cada sábado, y desde luego, requería de mayores cuidados dado el elevado número de reliquias que se guardaba en ella, además de embellecer con mayor esmero o adornar con flores aquella reliquia que tuviera previsto ser sacada en procesión el día de su fiesta.

Cuando fallecieron estas tres mujeres de la familia real, sus vestimentas y utensilios de uso diario pasaron a formar parte de la colección de las reliquias de las Descalzas Reales. Este fue el caso de sor Margarita de la Cruz, de quien se guarda como reliquia su túnica color marrón y su delantal de seda, color naranja, que usaba la infanta cuando arreglaba las reliquias.

\section{Referências}

ÁLVAREZ SOLAR-QUINTES, Nicolás. Reales Cédulas de Felipe II y adiciones de Felipe III en la escritura fundacional del Monasterio de las Descalzas de Madrid (1556-1601). Madrid: Instituto de Estudios Madrileños, 1962.

AMORÓS O.F.M., León. El monasterio de Santa Clara de Gandía y la familia ducal de los Borjas. Archivo Iberoamericano, v. 20 (1960), p. 441-486.

ANDRADA PFEIFFER, Ramón, Restauraciones y nuevas obras: Descalzas Reales, Reales Sitios v. 6, n. 22 (1969), pp. 65-67.

BASTIDA RODRÍGUEZ, Patricia, "Construcción patriarcal o transgresión femenina: las mártires cristianas en las re/visiones feministas de Anna Rossetti y Sara Maitland. In: CARRERA SUÁREZ, Isabel (Coord.). Mujeres históricas, mujeres narradas. Oviedo: Universidad, 2000, p. 191-207. 
BOUZA (Ed.), Fernando. Cartas de Felipe II a sus hijas. Madrid: Akal, 2008.

CARRILLO, P. Fray Juan. Relación Histórica de la real fundación del Monasterio de las Descalças de S. Clara de la villa de Madrid. Madrid, 1616.

CIEN-FUEGOS, Don Álvaro. La heroica vida, virtudes, y milagros del grande Francisco de Borja, antes duque cuarto de Gandía, después Tercero General de la Compañía de Jesús. Barcelona, 1754.

DALMASES, Cándido de. El Padre Francisco de Borja. Madrid: BAC, 1983.

GALENDE DÍAZ, Juan Carlos \& SALAMANCA LÓPEZ, Manuel. Epistolario de la emperatriz María de Austria: textos inéditos del Archivo de la Casa de Alba. Madrid: Nuevos Escritores, 2004.

GARCÍA HERNÁN, Enrique. Francisco de Borja, Grande de España. Valencia: Editorial Alfons El Magnanim, 1999.

GARCÍA SANZ, Ana, La idea y el espacio: Juana de Austria y el Monasterio de las Descalzas Reales. In: GARCÍA SANZ, Ana (Coord.). Las Descalzas Reales. Orígenes de una comunidad religiosa en el siglo XVI. Madrid: Patrimonio Nacional y Caja Madrid Fundación, 2010, p. 9-32.

GARCÍA SANZ, Ana, Arte y religiosidad en los conventos reales: huellas del carmelo en los patronatos regios. Librosdelacorte.es, v. 9, n. 6 (2014), p. 1-5.

GARCÍA SANZ, Ana \& SÁNCHEZ HERNÁNDEZ, Leticia, Guía Reales Monasterios de Madrid. Las Descalzas y la Encarnación. Madrid: Patrimonio Nacional, 2014.

GONZÁLEZ LOPO, Domingo Luis. El papel de las reliquias en las prácticas religiosas de los siglos XVII y XVIII. In: ÁLVAREZ SANTALÓ, León Carlos \& CREMADES GRIÑÁN, Carmen María (Eds.). Mentalidad e ideología en el Antiguo Régimen, II Reunión Científica de la Asociación española de Historia Moderna. Murcia: FEHM, 1993, v. II, p. 247-260.

GUERRA DE LA VEGA, Ramón. Guía para visitar las iglesias y conventos del Antiguo Madrid. Madrid: Gráficas Monterreina, 1996.

GIL RUIZ, Silvia María. Perfil sociológico de las religiosas que habitaron en el convento de las Descalzas Reales durante el reinado de Carlos II. Revista Madrid, Revista de Arte, geografia e Historia, v. 3 (2000), p. 31-56.

JIMÉNEZ PABLO, Esther. Reinas fundadoras en época moderna: el ejemplo de la reina Margarita de Austria (1584-1611). In: FERNÁNDEZ CORDERO, María Jesús, PIZARRO LLORENTE, Henar (Eds.). Las mujeres en el cristianismo: once calas en la historia. Santander: Sal Terrae, 2012, p. 125-136. 
JUNQUERA, Paulina \& JUNQUERA, Juan José. La Apoteosis de la Eucaristía. Descalzas Reales. Serie de Tapices. Reales Sitios, v. 6, n. 22 (1969), pp. 18-31.

LABRADOR ARROYO, Félix (Ed.), Diario de Hans Khevenhüller, embajador imperial en la corte de Felipe II. Madrid: Sociedad Estatal para la conmemoración de los centenarios de Felipe II y Carlos V, 2001.

MARTÍNEZ MILLÁN, José. La emperatriz María y las pugnas cortesanas en tiempos de Felipe II. In: BELENGUER CEBRIÀ, Ernest (Coord.). Felipe II y el Mediterráneo. Madrid: Sociedad Estatal para la Conmemoración de los Centenarios de Felipe II y Carlos V, 1999, v. 3, 1999, p. 143-162.

NIETO GALLO, Gratiniano. Una obra importante de Wenceslao Gamnizer: la arqueta de las Descalzas Reales de Madrid. Boletín del Seminario de Estudios de Arte y Arquitectura, vol. 6 (19391940), p. 177-196.

OLIVERAS GUART, Ángel, Amplias restauraciones en la clausura de las Descalzas Reales, Reales Sitios, v. 23 (1970), p. 73-76.

PEDREGAL RODRÍGUEZ, María Amparo, Las mártires cristianas: género, violencia y dominación del cuerpo femenino. Studia historica. Historia antigua, v. 18 (2000), pp. 277-294.

PÉREZ DE TUDELA, Almudena, Algunas joyas y relicarios de la reina Ana de Austria (15491580). In: RIVAS CARMONA, Jesús (Coord.). Estudios de platería: San Eloy 2012. Murcia: Universidad, 2012, p. 455-474.

PINTOS OSC., María Almudena. Creación y gestión del Monasterio: los primeros años de la comunidad de las Descalzas Reales. In: GARCÍA SANZ, Ana (Coord.). Las Descalzas Reales. Orígenes de una comunidad religiosa en el siglo XVI. Madrid: Patrimonio Nacional y Caja Madrid Fundación, 2010, p. 53-106.

PORTÚS PÉREZ, Javier. Las Descalzas Reales en la cultura festiva del Barroco. Reales Sitios: Revista del Patrimonio Nacional, v. 138 (1998), p. 2-12.

RODRÍGUEZ G. DE CEBALLOS, Alfonso. Arte y mentalidad religiosa en el Museo de las Descalzas Reales. Reales Sitios: Revista del Patrimonio Nacional, v. 138 (1998), p. 13-24.

RUIZ ALCÓN, María Teresa. Arquetas relicarios de las Descalzas Reales. Reales Sitios, v. 45 (1975), p. 28-36.

SÁNCHEZ, Magdalena. Los vínculos de sangre: la emperatriz María, Felipe II y las relaciones entre España y Europa central. In: MARTÍNEZ MILLÁN, José (Dir.). Felipe II (1527-1598): Europa y la monarquía católica. Madrid: Parteluz, v. 1, t. 2, 1998, p. 777-794. 
SÁNCHEZ, Magdalena. Where Palace and Convent met: the Descalzas Reales in Madrid. Sixteenth century journal: the journal of Early Modern Studies, USA, v. 1(2015), p. 53-82.

SANZ DE BREMOND Y MAYÁNS, Ana \& VILACOBA RAMOS, Karen María. Siguiendo el espíritu de Santa Clara: sor Margarita de la Cruz, la monja-infanta. In: PELÁEZ DEL ROSAL, Manuel(Coord.). El Franciscanismo en Andalucía: Clarisas, Concepcionistas y Terciarias regulares: Conferencias del X Curso de Verano. Córdoba, CajaSur, Asociación Hispánica de Estudios Franciscanos, 2006, p. 787-804.

SEBASTIÁN LOZANO, Jorge. Francisco de Borja, de criado a maestro espiritual de las mujeres Habsburgo. In: COMPANY, Ximo \& ALIAGA, Joan (Dirs.). San Francisco de Borja. Grande de España. Arte y espiritualidad en la cultura hispánica de los siglos XVI y XVI. Lleida: Centre d'Art d'Època Moderna, 2010, p. 67-90.

SICARD, Frédérique. Política en religión y religión en política: el caso de sor Margarita de la Cruz, archiduquesa de Austria. In: MARTÍNEZ MILLÁN, José \& GONZÁLEZ CUERVA, Rubén (Coords.). La dinastía de los Austria: las relaciones entre la Monarquía Católica y el Imperio. Madrid: Polifemo, v. 1, 2011, p. 631-646.

SOLER VILLALOBOS, María Paz, Felipe II, el hombre y el rey. In: González Alarcón, María Teresa (Coord.). El Escorial: Historia, Arte, Ciencia y Matemáticas, CD-Room, 2011.

TORMO Y MONZÓ, Elías. En las Descalzas Reales. Estudios históricos, iconográficos y artísticos. Madrid: Blass y Cia impr., 1917, v. I.

TORMO Y MONZÓ, Elías. Treinta y tres retratos en las Descalzas Reales. Estudios históricos, iconográficos y artísticos. Madrid: Junta de Iconografía Nacional, 1944.

VAN WYHE, Cordula. Court and Convent: The Infanta Isabella and her Franciscan Confessor Andrés de Soto. Sixteenth Century Journal, v. 35, n. 2 (2004), p. 411-445.

VERONELLI, Sara. La historia de Hans Khevenhüller, embajador cesáreo en la Corte de España. In: MARTÍNEZ MILLÁN, José (Dir.). Felipe II (1527-1598): Europa y la Monarquía Católica. Madrid: Parteluz, 1998, v. 4, p. 517-537.

VILACOBA RAMOS, Karen María. Entre Dios y la Corona: Relaciones epistolares de sor Ana Dorotea de Austria y Felipe IV. In: El franciscanismo en la Península Ibérica. Balance y perspectivas. I Congreso Internacional. Barcelona, 2005, p. 643-661.

VILACOBA RAMOS, Karen María \& MUÑOZ SERRULLA, María Teresa. Las religiosas de las Descalzas Reales de Madrid en los siglos XVI-XX: fuentes archivísticas. Hispania sacra, Madrid, v. 62, n.125(2010), p. 115-156. 


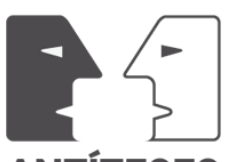

ANTÍTESES

ZURIAGA SENENT, Vicent Francesc, El dolor como triunfo: sacrificio, tortura y liberación de las mártires cristianas. Dossiers feministes 16 (2012), pp. 157-177.

Recebido em: 14-06-2017

Aceito em: 07-08-2017 